\title{
XXIV Brazilian National Meeting on Particles and Fields
}

The XXIV Brazilian National Meeting on Particles and Fields (Encontro Nacional de Física de Partículas e Campos), XXIVENFPC, which is a part of a series of annual topical meetings sponsored by the Brazilian Physical Society, SBF, took place at the Hotel Glória, in Caxambu, Minas Gerais, Brazil, from 30 September to 4 October 2003.

The XXIV ENFPC, which was was attended by 304 participants, covered topics in field theory, particle physics phenomenolgy, experimental high-energy physics, and gravitation and cosmology. The format of this meeting included six one-hour plenary talks, twelve 45-minutes parallel talks, four half-hour summary talks, fourteen parallel sessions of 15-minutes oral communications, and a poster session. One of the evenings was dedicated to a session in honour of professor Elisa Frota Pessôa. In the other evenings, there was a popular science talk by Prof. Carlos Ourivio Escobar, from Unicamp, open to the general public, in special to local high-school students, on "The misteries of the cosmic radiation", and a regular meeting of the Brazilian Physical Society, chaired by its President, Prof. Adalberto Fazzio.

The main goal of these meetings has always been an attempt to provide an up-to-date account of the main developments of the research areas related to experimental and theoretical particle physics, field theory and cosmology. They are a unique opportunity for the Brazilian physicists to present and discuss their own research results. These meetings are particularly relevant if we consider the size of the country and the difficulties to keep frequent interchanges throughout the year. In addition, the Latin American Center of Physics, CLAF, uses to support the participation of some Latin American scientists in order to strengthen the scientific collaboration among our neighboring countries. These meetings are attended by a large number of graduate students. In many cases, they are the first experience of these students at presenting a talk about their ongoing research work.

This special issue of the Brazilian Journal of Physics, with the proceedings of the XXIV ENFPC, contains the plenary, parallel and summary talks. The short oral communications are available in the conference web page, http://www.sbfl.sbfisica.org.br/eventos/enfpc/xxiv/. The plenary talks were presented by professores Peter van Nieuwenhuizen (Stony Brook, USA), Xin-Nian Wang (Lawrence Berkeley National Laboratory, USA), Hans Dijkstra (CERN, Switzerland), J. Martin (IAP, Paris), and A. Lasenby (MRAO-Cambridge, UK). The sixth plenary session was a round table to discuss "What is up in field theory", with professors Eduardo Marino (IF-UFRJ), Nathan Berkovits (IFT/UNESP) and Marcelo C. Gomes (IF-USP). The twelve parallel talks were presented by professors Walter Felipe Wreszinski (IF-USP), Fidel Schaposnik (Universidad de La Plata, Argentina), Marco Aurélio C. Kneipp (UERJ), M. Rebouças (CBPF), Vitório A. De Lorenci (UNIFEI), J. G. Pereira (IFT/UNESP), Arthur Maciel (Northern Illinois University, USA), Marcelo Leigui (UNICAMP), Ignacio Bediaga (CBPF), Victor Gonçalves (UFPEL), Pedro Mercadante (IF-USP), and Pedro de Holanda (UNICAMP). The summary talks were presented by professors Marcos Duarte Maia (UNB), Maria Beatriz Gay Ducati (UFRGS), Leandro de Paula (IF-UFRJ), and Dionisio Bazeia (UFPB). These proceedings also include the talk by Prof. David Reyna (Argonne National Laboratory, USA) who gave an overview of the project of construction of a neutrino experiment in Brazil.

This meeting was funded by the Brazilian federal agencies CNPq (Conselho Nacional de Desenvolvimento Científico e Tecnológico), FINEP (Financiadora de Estudos e Projetos), and CAPES (Coordenação de Aperfeiçoamento de Pessoal de Nível Superior), and by the local state agencies FAPESP (São Paulo), FAPERJ (Rio de Janeiro), FAPEMIG (Minas Gerais), and FAPERGS (Rio Grande do Sul). We also had the support of CLAF and of the graduate programs of several universities.

The Organizing Committee is grateful to the invited speakers and to all of the colleagues who contributed for the excellent scientific atmosphere of the meeting. Special thanks are also due to the staff of the Brazilian Physical Society, Eliana Maria Alves, Neusa M. Lucas Martin, Roberto C. Pereira, Fernando Luiz Braga, and Jean R. Buzoli, for the superb work of organization.

Luiz Agostinho Ferreira

Guest editor 